Bringing Earth-Abundant Plasmonic Catalysis to Light :

Gram-Scale Mechanochemical Synthesis and Tuning of Activity by Dual Excitation of Antenna and Reactor Sites

Quiroz, Jhon

2021-07-26

Quiroz , J , de Oliveira , P F M , Shetty , S , Oropeza , F E , de la Pena O'Shea , V A, Rodrigues, L C , Rodrigues, M P D S , Torresi , R M , Emmerling, F \& Camargo, P H C 2021 , ' Bringing Earth-Abundant Plasmonic Catalysis to Light : Gram-Scale Mechanochemical Synthesis and Tuning of Activity by Dual Excitation of Antenna and Reactor Sites ' , ACS Sustainable Chemistry \& Engineering , vol. 9 , no. 29 , pp. 9750-9760 . https://doi.org/10.1021/

http://hdl.handle.net/10138/333076

https://doi.org/10.1021/acssuschemeng.1c02063

cc_by

publishedVersion

Downloaded from Helda, University of Helsinki institutional repository.

This is an electronic reprint of the original article.

This reprint may differ from the original in pagination and typographic detail.

Please cite the original version. 


\section{Bringing Earth-Abundant Plasmonic Catalysis to Light: Gram-Scale Mechanochemical Synthesis and Tuning of Activity by Dual Excitation of Antenna and Reactor Sites}

Jhon Quiroz, ${ }^{\perp}$ Paulo F. M. de Oliveira, ${ }^{\perp}$ Shwetha Shetty, Freddy E. Oropeza,

Víctor A. de la Peña O’Shea, Lucas C. V. Rodrigues, Maria P. de S. Rodrigues, Roberto Manuel Torresi, Franziska Emmerling, and Pedro H. C. Camargo*

Cite This: ACS Sustainable Chem. Eng. 2021, 9, 9750-9760

Read Online

ACCESS | Lill Metrics \& More | 回 Article Recommendations ｜ＳＳ Supporting Information

ABSTRACT: The localized surface plasmon resonance (LSPR) excitation in plasmonic nanoparticles (NPs) in the visible and near-infrared ranges is currently at the forefront of improving photocatalytic performances via plasmonic photocatalysis. One bottleneck of this field is that the NPs that often display the best optical properties in the visible and near-infrared ranges are based on expensive noble metals such as silver $(\mathrm{Ag})$ and gold $(\mathrm{Au})$. While earth-abundant plasmonic materials have been proposed together with catalytic

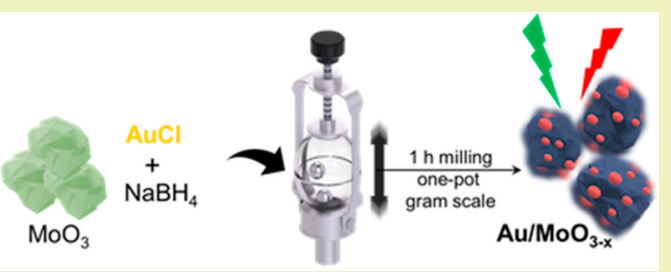
metals in antenna-reactor systems, their performances remain limited by their optical properties. Importantly, the synthesis of plasmonic photocatalysts remains challenging in terms of scalability while often requiring several steps, high temperatures, and special conditions. Herein, we address these challenges by developing a one-pot, gram-scale, room-temperature synthesis of earth-abundant plasmonic photocatalysts while improving their activities beyond what has been dictated by the LSPR excitation of the plasmonic component. We describe the mechanochemical synthesis of earth-abundant plasmonic photocatalysts by using $\mathrm{MoO}_{3}$ (antenna) and Au (reactor) NPs as a proof-of-concept example and demonstrate that the dual plasmonic excitation of antenna and reactor sites enables the tuning of plasmonic photocatalytic performances toward the reductive coupling of nitrobenzene to azobenzene as a model reaction. In addition to providing a pathway to the facile and gramscale synthesis of plasmonic photocatalysts, the results reported herein may open pathways to improved activities in plasmonic catalysis.

KEYWORDS: $\mathrm{MoO}_{3}$, Au nanoparticles, Localized surface plasmon resonance, Plasmonic photocatalysis, Nitrobenzene reduction

\section{INTRODUCTION}

Although mechanochemistry is a mature field, ${ }^{1}$ there has been a renewed interest in the development of mechanochemical approaches for the synthesis of inorganic materials, such as oxides $^{2-5}$ and metal nanoparticles (NPs). ${ }^{6-12}$ This has been driven by attractive features of mechanochemistry relative to commonly reported batch solution phase strategies. Examples include the lack of need for reaction workup (or simple workup when needed), robustness, simplicity, the possibility of not using any solvents, and the potential for scalability. ${ }^{7}$ This is particularly important for the synthesis of metal NPs, which is challenging in terms of large-scale synthesis, often requiring the use of solvents and demanding several steps for purification and isolation via successive rounds of centrifugation and removal of the supernatant. Nevertheless, metal NPs present unique electronic, optical, and chemical properties that can be pivotal to new imaging and therapeutical applications, ${ }^{13}$ to allow more sustainable molecular transformations, ${ }^{14}$ and to enable a transition to a more sustainable society and circular economy. $^{15}$
Among the key properties of metal NPs, "localized surface plasmon resonance" (LSPR) refers to the collective oscillation of the electron cloud in the NPs in response to an incoming electromagnetic radiation. ${ }^{16-18}$ This takes place at a characteristic frequency that is dependent on the physicochemical parameters of the NPs and the dielectric constant of the environment. It has been demonstrated that, in addition to outstanding optical properties, LSPR excitation can contribute to accelerate or drive several chemical reactions. ${ }^{18,19}$ In fact, NPs supporting LSPR excitation in the visible and nearinfrared ranges (plasmonic NPs) are currently at the forefront of improving photocatalytic performances. ${ }^{20-22}$ This field, named "plasmonic catalysis" (or "plasmonic photocatalysis"), allows for much milder conditions and alternative reaction

Received: March 25, 2021

Revised: June 25, 2021

Published: July 12, 2021 
pathways that are not possible via conventional, thermally activated transformations. ${ }^{23}$ It allows the use of sunlight as an energy source to accelerate and drive chemical reactions and provide new strategies for the control over reaction selectivity, ${ }^{24}$ although this remains one of the current challenges in the field. Another major bottleneck is that the NPs that often display the best optical properties (LSPR excitation) in the visible and near-infrared ranges are based on expensive noble metals such as silver $(\mathrm{Ag})$ and gold $(\mathrm{Au}){ }^{25,26}$ In this context, examples of the use of $\mathrm{Al}^{27,28} \mathrm{Mg}^{29} \mathrm{Cu},{ }^{30}$ metal nitrides, ${ }^{31}$ and metal oxides ${ }^{32-35}$ as alternative plasmonic materials have been reported. Nevertheless, two main challenges remain: (i) the syntheses of these earth-abundant materials remain limited in terms of scalability while often requiring several steps, high temperatures, and special conditions (such as inert atmosphere or harsh environments) $;^{34}$ and (ii) their performances remain limited by the LSPR excitation of the plasmonic component both when the plasmonic NPs act as the catalysts and when the plasmonic NPs are combined with a catalytic component to form a plasmonic-catalytic antenna-reactor morphology design. ${ }^{36-41}$

In this paper, we aim to address both challenges, i.e., to develop a one-pot, gram-scale, room-temperature synthesis of earth-abundant plasmonic photocatalysts while improving their activities beyond what has been dictated by the LSPR excitation of the plasmonic component. We achieve this by developing a mechanochemical approach for the synthesis of earth-abundant plasmonic photocatalysts and by demonstrating that the dual plasmonic excitation of antenna and reactor sites in antenna-reactor plasmonic-catalytic NPs enables performances that move beyond that observed for the individual excitation of either plasmonic or catalytic sites. Specifically, by using $\mathrm{MoO}_{3}$ and Au NPs as a proof-of-concept example, we report on a mechanochemical approach that enabled the one-pot, room temperature, gram-scale synthesis of $\mathrm{Au}$ NPs supported on plasmonic $\mathrm{MoO}_{3}\left(\mathrm{Au} / \mathrm{MoO}_{3} \mathrm{P}\right)$ in only $1 \mathrm{~h}$. This antenna-reactor NP design contains plasmonic $\mathrm{MoO}_{3}$ as the support (antenna) and Au NPs as the catalytic (reactor) sites that also support LSPR excitation. By employing the reductive coupling of nitrobenzene to azobenzene via $\mathrm{H}$ atom transfer catalyzed by $\mathrm{Au}$ as a model transformation, we show that the activity under light excitation can be enhanced by exciting the LSPR of both the antenna and reactor NPs. This dual excitation enabled achievement of activities that are beyond what is achieved by the LSPR excitation of either $\mathrm{MoO}_{3}$ or $\mathrm{Au}$ components, showing that the proposed dual LSPR excitation concept can provide an effective pathway to improved performances in plasmonic catalysis.

\section{EXPERIMENTAL SECTION}

Materials and Methods. Molybdenum(VI) oxide powder ( $\geq 99.5 \%$, Sigma-Aldrich), sodium borohydride $\left(\mathrm{NaBH}_{4}, 98 \%\right.$, Fisher Chemical), gold(I) chloride (AuCl, 99\%, Sigma-Aldrich), absolute ethanol $\left(\mathrm{C}_{2} \mathrm{H}_{5} \mathrm{OH}\right.$, Sigma), isopropanol (IPA, HPLC grade, SigmaAldrich), and potassium hydroxide ( $\mathrm{KOH}, 86.8 \%$, Fisher Chemical) were all used as received without further purification. For the electrochemical measurements, potassium hydroxide $(\mathrm{KOH}, 90 \%$ Sigma-Aldrich), Nafion 5\% $\left(\mathrm{C}_{7} \mathrm{HF}_{13} \mathrm{O}_{5} \mathrm{~S} \cdot \mathrm{C}_{2} \mathrm{~F}_{4}, 15-20 \%\right.$, SigmaAldrich), and carbon black Vulcan XC-72R were employed. Deionized water $(\mathrm{DI}, 18.2 \mathrm{M} \Omega \cdot \mathrm{cm})$ was used to prepare all the solutions.

Transmission electronic microscopy (TEM) images were taken on a Tecnai F20 electron microscope operating at an accelerating voltage of $200 \mathrm{kV}$. Before TEM observations, one part of the samples was redispersed in ethanol with an ultrasound bath and deposited onto carbon-coated copper grids. The average diameter of the resulting gold nanoparticles in the $\mathrm{Au} / \mathrm{MoO}_{3-x}$ sample was determined by individually measuring the diameters of 50 NPs. Scanning electron microscopy (SEM) images were obtained with a Hitachi S-4800 field emission microscope. The samples were prepared by dropping an ethanolic suspension onto an oxidized silicon wafer. UV/visible diffuse reflectance spectroscopy (DRS) characterization of the powder samples was carried out on a PerkinElmer Lambda $950 \mathrm{UV} /$ vis/NIR spectrometer equipped with an integrating sphere. Spectralon (99\% reflectance) was used as the standard. The spectra were acquired from 850 to $200 \mathrm{~nm}$ using a step size of $1 \mathrm{~nm}$. Powder X-ray diffraction (PXRD) data were collected on a Bruker D8 Advance in BraggBrentano geometry using $\mathrm{Cu} \mathrm{K} \alpha(\lambda=1.5406 \AA)$ with a $\mathrm{Ni}$ filter. Diffraction data were collected over a range of $10-70^{\circ} 2 \theta$ (step width $0.02^{\circ} 2 \theta$, count time $1 \mathrm{~s} / \mathrm{step}$ ). The diffraction patterns have been indexed by comparison with the Joint Committee on Powder Diffraction Standards (JCPDS) files. The Raman analysis was performed with an MS3504i monochromator spectrograph and an NT-MDT NTEGRA microscope. The samples were qualitatively analyzed by drop casting a small amount of catalyst suspended on 10 $\mu \mathrm{L}$ of ethanol over silicon wafers. Once the solvent evaporated, the calibration was carried out by irradiating a silicon wafer and adjusting its peak to be $520.7 \mathrm{~cm}^{-1}$. The metal content in the Supporting Information was measured by flame atomic emission spectroscopic (AES) analysis with an Agilent Technologies 4100 MP AES. X-ray photoelectron spectroscopy (XPS) measurements were recorded by using a lab-based spectrometer (SPECS GmbH, Berlin) with a monochromatic $\mathrm{Al} \mathrm{K} \alpha$ source $(h v=1486.6 \mathrm{eV})$ operated at $50 \mathrm{~W}$ as the excitation source. In the spectrometer, the X-rays are focused with a $\mu$-FOCUS 600 monochromator onto a $300 \mu \mathrm{m}^{2}$ spot on the sample and the data are recorded with a PHOIBOS 150 NAP 1D-DLD analyzer in fixed analyzer transmission (FAT) mode. The pass energy was set to $40 \mathrm{eV}$ for survey scans and $20 \mathrm{eV}$ for high-resolution regions. Recorded spectra were calibrated against the $\mathrm{C} 1 \mathrm{~s}$ internal reference. Data interpretation was done with Casa XPS. A Shirley background was employed.

Temperature-programmed desorption (TPD) was performed on a fixed bed quartz microreactor (length, $200 \mathrm{~mm}$; width, $5 \mathrm{~mm}$ ) in a CATLAB unit from Hiden Analytical. The sample $(30 \mathrm{mg})$ was first heated to $50{ }^{\circ} \mathrm{C}$ for $1 \mathrm{~h}$ under Ar flow in order to remove gaseous adsorbed species. Then, the sample was heated at $10^{\circ} \mathrm{C} \mathrm{min}^{-1}$ to 800 ${ }^{\circ} \mathrm{C}$ also under $\mathrm{Ar}$ as carrier gas. The gas products were measured by online mass spectrometry (Hiden Analytical QIC-20 MS). The photoluminescence (PL) spectra were measured in an Edinburg FLS980 with an excitation and emission double monochromator using a $450 \mathrm{~W}$ xenon lamp as the excitation source. The emission spectra of the powder were collected with a Front Face sample holder. All measurements were performed at room temperature. For the surface determination, an ASAP 2020 from Micromeritics was used and the isotherm was measured with nitrogen at $77 \mathrm{~K}$. The specific surface areas were hereby calculated from the adsorption branch, in a relative pressure range of $0.05 \leq p / p_{0}<0.2$ of the isotherm using the multipoint method of Brunauer, Emmett, and Teller (BET). ${ }^{42}$

Photocurrent (on/off $j-t$ transients; current density vs time) and electrochemical impedance spectroscopic (EIS) measurements were recorded by employing the hydrogen evolution reaction (HER) under 533 and $650 \mathrm{~nm}$ laser irradiation. A three-electrode electrochemical cell was applied, with a reversible hydrogen electrode (RHE) as the reference electrode and a $\mathrm{Pt}$ wire as the counter electrode. The working electrode was a glassy carbon electrode $(d=2.5 \mathrm{~mm})$ modified by drop casting $21 \mu \mathrm{L}$ of catalyst ink ( $20 \mathrm{mg}$ of carbon black Vulcan XC-72R, $20 \mathrm{mg}$ of catalyst, and $10 \mathrm{~mL}$ of water) and $7 \mu \mathrm{L}$ of a Nafion $0.05 \%$ solution. $\mathrm{KOH}\left(1 \mathrm{~mol} \mathrm{~L}^{-1}\right)$ was used as the electrolyte, and the cell was $\mathrm{N}_{2}$-saturated to avoid reactive oxygen species formation. Moreover, the hydrodynamic condition of $1600 \mathrm{rpm}$ controlled by a Pine AFMSRCE rotating disk electrode was used to avoid bubble accumulation on the working electrode surface. The potential step perturbation and the EIS were executed and controlled by a PGSTAT302N Autolab potentiostat/galvanostat. In both cases 
the potential was set to $-0.45 \mathrm{~V}_{\mathrm{RHE}}$. A chopped light was used as the light source for the $j-t$ transients, whereas a continuous light source was used for the impedance measurements. The currents were normalized by the geometric area of the working electrode $(A=0.196$ $\mathrm{cm}^{2}$ ).

Mechanochemical Synthesis of Plasmonic $\mathrm{MoO}_{3}\left(\mathrm{MoO}_{3} \mathrm{P}\right)$. Plasmonic $\mathrm{MoO}_{3}\left(\mathrm{MoO}_{3} \mathrm{P}\right)$ was synthesized in a ball-milling device and was based on the partial reduction between commercial $\mathrm{MoO}_{3}$ $\left(\mathrm{MoO}_{3} \mathrm{C}\right)$ and sodium borohydride $\left(\mathrm{NaBH}_{4}\right)$ precursors. The milling experiments were conducted on a vertical vibratory ball mill (Pulverisette 23, Fritsch) at $50 \mathrm{~Hz}$ using a PMMA milling jar $(10 \mathrm{~mL}$ ) with a single zirconia milling ball (diameter $=10 \mathrm{~mm} ; 3.14 \mathrm{~g}$ ). The $\mathrm{MoO}_{3} \mathrm{P}$ sample was obtained after $1 \mathrm{~h}$ of milling of commercial $\mathrm{MoO}_{3}(974.4 \mathrm{mg})$ and $\mathrm{NaBH}_{4}(26.0 \mathrm{~g})$, keeping a molar ratio of $\mathrm{MoO}_{3}: \mathrm{BH}_{4}=0.1$. In this process, the metal precursor was weighed directly in the milling jar. A control sample was obtained after milling only commercial $\mathrm{MoO}_{3}$ powder without the reductant for $1 \mathrm{~h}$, identified as $\mathrm{MoO}_{3} \_\mathrm{M}$. The resultant powders were centrifuged and washed with water and absolute ethanol via successive rounds of centrifugation, resuspension, and removal of the supernatant. Then, the product was dried at $80{ }^{\circ} \mathrm{C}$ overnight.

Mechanochemical Synthesis of Au NPs Supported on Plasmonic $\mathrm{MoO}_{3}\left(\mathrm{Au} / \mathrm{MoO}_{3} \mathrm{P}\right)$. The one-pot gram-scale synthesis of supported $\mathrm{Au}$ NPs in $\mathrm{MoO}_{3} \mathrm{P}\left(\mathrm{Au} / \mathrm{MoO}_{3} \mathrm{P}\right)$ was performed in situ by using the ball-milling device described above. In a typical synthesis, $\mathrm{AuCl}\left(57.4 \mathrm{mg} ; \sim 5 \mathrm{wt} \%\right.$ to $\mathrm{MoO}_{3}$ ) was premilled with commercial $\mathrm{MoO}_{3}(974.4 \mathrm{mg})$ for $10 \mathrm{~min}$ to ensure a better distribution of the metal precursor over the support. Then, $\mathrm{NaBH}_{4}$ (26 mg) was added to the jar. The resultant powder mixture was milled for $1 \mathrm{~h}$, washed, and dried following the same protocol described above (Figure 1).

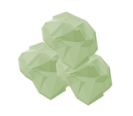

Commercial $\mathrm{MoO}_{3}$
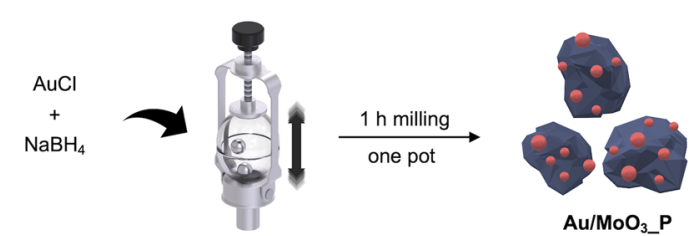

$\mathrm{Au} / \mathrm{MoO}_{3} \mathrm{P}$
Figure 1. Representation of the mechanochemical, ball-milling synthesis of $\mathrm{Au} / \mathrm{MoO}_{3} \mathrm{P}$ photocatalysts employing commercial $\mathrm{MoO}_{3}, \mathrm{AuCl}$, and $\mathrm{NaBH}_{4}$ as starting materials.

Photocatalytic Tests. The nitrobenzene (NB) reduction was performed in a $100 \mathrm{~mL}$ Schlenk flask. In a typical procedure, the photocatalyst $(5 \mathrm{mg})$ was suspended in $5 \mathrm{~mL}$ of a $0.1 \mathrm{M}$ solution of $\mathrm{KOH}$ in IPA $(0.02 \mathrm{mmol})$. Afterward, $0.15 \mathrm{mmol}$ of $\mathrm{NB}$ was added and the resulting mixture was homogenized for $10 \mathrm{~min}$ in an ultrasound bath. After the solution was bubbled with argon (Ar) for 5 min, the flask was sealed with a balloon that was prefilled with $\mathrm{Ar}$ at a pressure of $\sim 1 \mathrm{~atm}$. Two flasks were loaded at the same time to perform the reaction under light excitation and dark conditions separately. The experiments under dark (light off) conditions were performed by covering the flask with aluminum foil. For the experiment under light excitation (light on), the reactor was irradiated by using four Kessil PR 160 LEDs with 530 and/or $740 \mathrm{~nm}$ irradiation at a reactor-lamp distance of $6 \mathrm{~cm}$ having a total irradiance of $14.34 \mathrm{~mW} / \mathrm{cm}^{-2}$ and a cooling fan positioned above the reaction flask. For the experiment employing two different wavelengths, the reactor was irradiated by using two $740 \mathrm{~nm}$ Kessil PR 160 LEDs and two $530 \mathrm{~nm}$ Kessil PR 160 LEDs having the same irradiance as described above. In all the experiments, the reaction mixture was stirred with a Teflon-coated magnetic stirrer, the temperature was settled at $70{ }^{\circ} \mathrm{C}$ with a silicon bath, and the reaction was allowed to proceed for $6 \mathrm{~h}$.

The reaction products were analyzed by gas chromatography (GC). Two aliquots of $1.5 \mathrm{~mL}$ were collected for each reactor batch after the reaction time had been completed. The catalyst was separated by centrifugation (13000 rpm, $10 \mathrm{~min}$ ), and the liquid sample was filtrated with syringe filters $(0.22 \mu \mathrm{m}$ filter diameter $)$ and injected in a Shimadzu NEXIS GC-2030 gas chromatograph. The GC was equipped with a flame ionization detector, which enabled the separation and quantification of all reaction products by using a Crossbond SH-Rxi-5ms $(30 \mathrm{~m} \times 0.25 \mathrm{~mm} \times 0.25 \mu \mathrm{m})$ capillary column. The following temperature program was used during the analysis: $70^{\circ} \mathrm{C}$ for $1 \mathrm{~min} ; 6^{\circ} \mathrm{C} \mathrm{m^{-1 }}$ until $85{ }^{\circ} \mathrm{C}$ and then $100{ }^{\circ} \mathrm{C}$ $\min ^{-1}$ until $300^{\circ} \mathrm{C}$. For the $t=0$ samples, a solution containing 0.15 mmol of NB in IPA was injected before each catalytic test following the same protocol stated above. The nitrobenzene conversion $\left(X_{\mathrm{NB}}\right.$, $\%)$ was calculated with the following equation:

$$
X_{\mathrm{NB}}(\%)=\frac{A_{\mathrm{NBi}}-A_{\mathrm{NB} t}}{A_{\mathrm{NBi}}} \times 100
$$

where $A_{\mathrm{NBi}}$ and $A_{\mathrm{NB} t}$ are the chromatographic areas of nitrobenzene in the samples at time $t=0$ and $t$, respectively. The product selectivity was calculated using eq 2 :

$$
S_{i}(\%)=\frac{A_{\mathrm{p} i}}{\sum A_{j}} \times 100
$$

where $A_{\mathrm{p} i}$ is the chromatographic area of product $\mathrm{p} i$ and $\sum A_{j}$ is the sum of the chromatographic area of all detected products.

\section{RESULTS AND DISCUSSION}

The developed mechanochemical approach for the one-pot synthesis of $\mathrm{Au}$ NPs supported on plasmonic $\mathrm{MoO}_{3}$ (Au/ $\mathrm{MoO}_{3} \mathrm{P}$ ) photocatalysts is shown in Figure 1. This strategy relied on the use of $\mathrm{MoO}_{3}$ (commercial), $\mathrm{AuCl}$, and $\mathrm{NaBH}_{4}$ as starting materials. Importantly, this route enabled us to obtain the $\mathrm{Au} / \mathrm{MoO}_{3} \mathrm{P}$ photocatalysts at the gram scale, in a single step, in $1 \mathrm{~h}$, and at room conditions. In this process, $\mathrm{NaBH}_{4}$ has a dual function: (i) it acts as a reducing agent to generate Au NPs and (ii) it acts as a source of hydrogen species that can intercalate into the $\mathrm{MoO}_{3}$ structure. This is important as it has been established that hydrogen intercalation into the $\mathrm{MoO}_{3}$ structure leads to the formation of hydrogen molybdenum bronzes such as $\mathrm{H}_{x} \mathrm{Mo}_{x}{ }^{5+} \mathrm{Mo}_{1-x}{ }^{6+} \mathrm{O}_{3}$ and substoichiometric molybdenum trioxide $\left(\mathrm{MoO}_{3-x}\right)$ that support LSPR excitation in the visible and near-infrared ranges. ${ }^{43,44}$

Figure 2A shows the powder XRD patterns of the commercial $\mathrm{MoO}_{3}$ employed as the starting material $\left(\mathrm{MoO}_{3} \mathrm{C}\right)$, the plasmonic $\mathrm{MoO}_{3}$ sample obtained after ball milling $\mathrm{MoO}_{3}$ with $\mathrm{NaBH}_{4}$ in the absence of $\mathrm{AuCl}\left(\mathrm{MoO}_{3} \mathrm{P}\right)$, and the $\mathrm{Au} / \mathrm{MoO}_{3} \mathrm{P}$ samples obtained after ball milling $\mathrm{MoO}_{3}$ with $\mathrm{NaBH}_{4}$ and $\mathrm{AuCl}$. The starting $\mathrm{MoO}_{3}$ solid displayed a yellowish color, and the XRD patterns showed dominant diffraction peaks at $12.7,25.7$, and $38.92^{\circ}$ ascribed to the (020), (040), and (060) crystal planes of orthorhombic $\alpha$ $\mathrm{MoO}_{3}$ (JCPDS No. 050508, black trace). The $\mathrm{MoO}_{3-} \mathrm{P}$ sample displayed a dark blue color (indicative of optical properties in the visible range). The corresponding XRD pattern (blue trace) shows that no phase transition took place, and thus, the orthorhombic $\alpha-\mathrm{MoO}_{3}$ phase was maintained. This is an indication that the milling process is mostly consistent with a fracture-only process and that no friction, which could lead to a transition to a monoclinic phase, has occurred. ${ }^{45}$ On the other hand, the intensities of the diffraction peaks were reduced relative to the starting $\mathrm{MoO}_{3}$. In this case, it is plausible that the reducing environment along with the comminution process and the mechanical energy provided by the ball-milling procedure allowed the topotactic intercalation of hydrogen into the $\mathrm{MoO}_{3}$ structure while keeping the orthorhombic crystal phase. This is known as a type I intercalation, in which the $x$ values in the $\mathrm{H}_{x} \mathrm{Mo}_{x}{ }^{5+} \mathrm{Mo}_{1-x}{ }^{6+} \mathrm{O}_{3}$ 
A

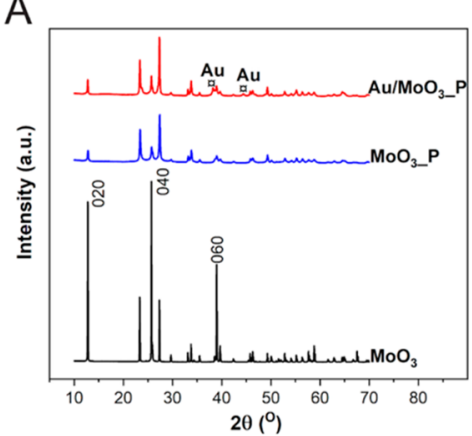

D

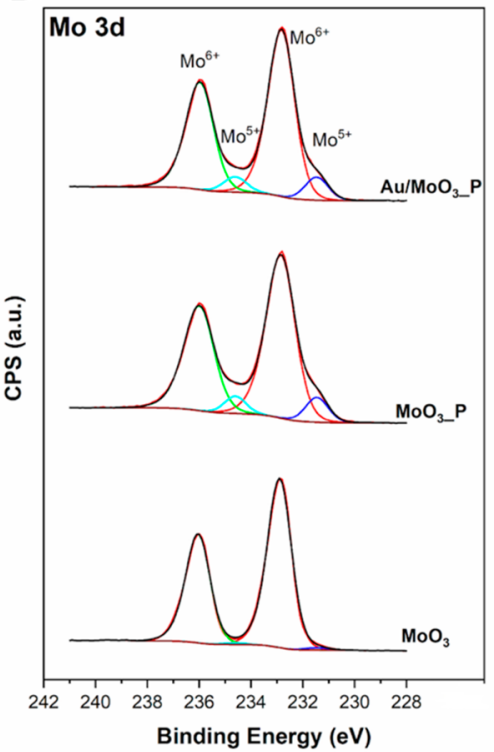

B

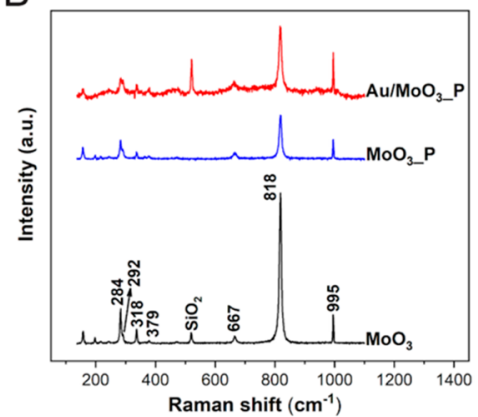

E

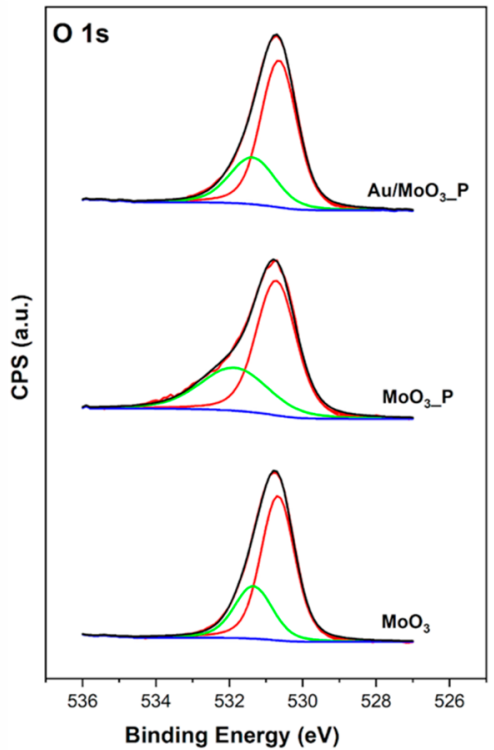

C

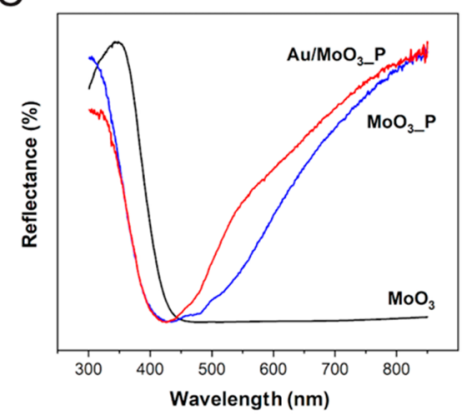

F

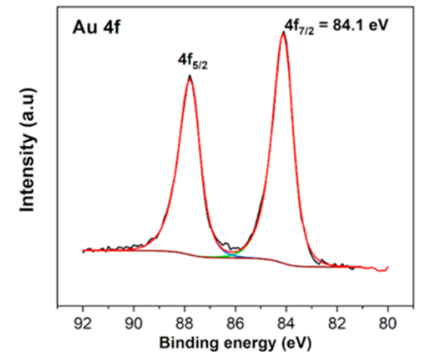

G

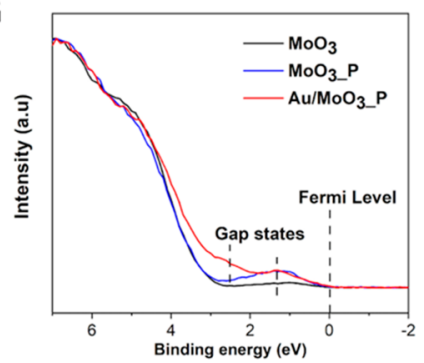

Figure 2. (A) XRD patterns; (B) Raman spectra; (C) DRS spectra; (D-F) XPS spectra of Mo 3d (D), O 1s (E), and Au 4f (F) core levels; and (G) XPS valence spectra for commercial $\mathrm{MoO}_{3}\left(\mathrm{MoO}_{3} \mathrm{C}\right.$, black trace), plasmonic $\mathrm{MoO}_{3}$ obtained after ball milling in the presence of $\mathrm{NaBH}_{4}$ $\left(\mathrm{MoO}_{3} \mathrm{P}\right.$, blue trace), and $\mathrm{Au}$ NPs supported on plasmonic $\mathrm{MoO}_{3}$ produced by ball milling $\mathrm{MoO}_{3}$ and $\mathrm{AuCl}$ in the presence of $\mathrm{NaBH} \mathrm{H}_{4}(\mathrm{Au} /$ $\mathrm{MoO}_{3}{ }_{-} \mathrm{P}$, red trace). In $(\mathrm{G})$, the dashed lines show a comparison of the Fermi level positions for the samples.

generated bronzes are in the range $0.23<x<0.40$. Figure S1 shows the normalized XRD patterns for both $\mathrm{MoO}_{3} \mathrm{P}$ and $\mathrm{Au} / \mathrm{MoO}_{3} \mathrm{P}$ materials depicting the formation of $\mathrm{H}_{x} \mathrm{MoO}_{3}$ species as a result of hydrogen intercalation. Regarding the decrease in the intensity of (020), (040), and (060) crystal planes, this can be assigned to the decrease in crystallinity as a result of $\mathrm{H}^{+}$intercalation ${ }^{46,47}$ and due to the smaller crystallite size after the grinding process. In this case, the crystallite sizes as calculated from Scherrer's formula corresponded to 149.1, 46.4 , and $53.4 \mathrm{~nm}$ for $\mathrm{MoO}_{3} \mathrm{C}, \mathrm{MoO}_{3} \mathrm{P}$, and $\mathrm{Au} / \mathrm{MoO}_{3} \mathrm{P}$ samples, respectively.

It has been established that the hydrogen intercalation in $\mathrm{Pt} /$ $\mathrm{MoO}_{3}$ and $\mathrm{Ru} / \mathrm{MoO}_{3}$ materials occurs via a hydrogen spillover following the dissociation of $\mathrm{H}_{2}$ at the $\mathrm{Pt}$ and $\mathrm{Ru}$ sites. ${ }^{36,38}$ The hydrogen intercalation leads to the reduction of Mo species and the formation of oxygen vacancies that give rise to LSPR bands in the visible and near-IR regions. ${ }^{36,38}$ Here, the intercalation of hydrogen does not occur because of hydrogen spillover as it was also observed in the absence of Au NPs for the $\mathrm{MoO}_{3} \mathrm{P}_{2}$ material. $\mathrm{H}_{2}-\mathrm{TPD}$ data for $\mathrm{MoO}_{3} \mathrm{P}$ and $\mathrm{Au} /$ $\mathrm{MoO}_{3} \mathrm{P}$ samples do not show $\mathrm{MS}$ signals due to $\mathrm{H}_{2}$ desorption from the samples (Figure S2). In these systems, $\mathrm{NaBH}_{4}$ acts as the hydrogen source and ball milling provides the energy input for the $\mathrm{H}$ intercalation into the $\mathrm{MoO}_{3}$ structure, which then leads to the formation of oxygen vacancies and gives rise to LSPR properties in the visible and near-IR regions. ${ }^{36,38}$ The intercalated $\mathrm{H}^{+}$ions are reported to be bonded with the terminal oxygen atoms enlarging the interlayer spacings. Interestingly, it has been shown that these intercalating ions eventually take oxygen atoms from the crystal phase, forming substoichiometric molybdenum trioxide $\left(\mathrm{MoO}_{3-x}\right)$, which displays a strong blue color that arises from LSPR. ${ }^{48-50}$

Finally, the XRD pattern for the sample containing Au NPs $\left(\mathrm{Au} / \mathrm{MoO}_{3} \mathrm{P}\right.$, red trace) showed diffraction patterns similar to those detected for the $\mathrm{MoO}_{3} \mathrm{P}$ sample and the diffraction peaks assigned to $\mathrm{Au}$ (JCPDS No. 00-004-0784). The XRD data show that the reported mechanochemical approach could successfully convert $\mathrm{AuCl}$ to $\mathrm{Au} \mathrm{NPs}$ and the commercial $\mathrm{MoO}_{3}$ to plasmonic $\mathrm{MoO}_{3}\left(\mathrm{MoO}_{3} \mathrm{P}\right)$. These results are also supported by Raman analyses (Figure 2B). For $\mathrm{MoO}_{3} \mathrm{C}$, characteristic bands at 284, 292, 338, 379, 667, 818, and 995 $\mathrm{cm}^{-1}$ assigned to the orthorhombic $\alpha-\mathrm{MoO}_{3}$ structure were detected. ${ }^{43}$ These bands are still observed for the samples after ball milling $\left(\mathrm{MoO}_{3} \mathrm{P}\right.$ and $\mathrm{Au} / \mathrm{MoO}_{3} \mathrm{P}$, blue and red traces, respectively). However, upon hydrogen intercalation, there is a decrease in intensity and broadening of the Raman bands. This indicates the decrease in the crystallinity of the $\alpha-\mathrm{MoO}_{3}$ phase 
due to hydrogen intercalation and the milling procedure, as also indicated by XRD data.

Next, the diffuse reflectance spectra (DRS) were recorded to evaluate the optical properties of the samples (Figure 2C). The starting, the commercial $\mathrm{MoO}_{3}$ sample $\left(\mathrm{MoO}_{3}\right.$, black trace) displayed a typical semiconductor profile with an absorption band edge around $450 \mathrm{~nm}$. No bands were further detected in the visible region. The blue trace in Figure $2 \mathrm{C}$ presents the DRS spectrum for plasmonic $\mathrm{MoO}_{3}\left(\mathrm{MoO}_{3} \mathrm{P}\right)$, showing the presence of an intense plasmon absorption in the $500-800 \mathrm{~nm}$ region assigned to the LSPR due to the formation of oxygen vacancies upon $\mathrm{H}^{+}$intercalation. ${ }^{43}$ This absorption starts from $500 \mathrm{~nm}$ and increases in intensity as it progresses toward 800 $\mathrm{nm}$. This observation provides further evidence that allows us to validate our mechanochemical approach for the synthesis of $\mathrm{MoO}_{3-x}$ as a support displaying plasmonic properties. Figure $2 \mathrm{C}$ also shows the DRS spectrum for Au NPs supported onto plasmonic $\mathrm{MoO}_{3}\left(\mathrm{Au} / \mathrm{MoO}_{3} \mathrm{P}\right.$, red trace $)$. In this material, in addition to this signal in the $500-800 \mathrm{~nm}$ due to the LSPR band in plasmonic $\mathrm{MoO}_{3}$, a shoulder band in the 450-550 nm region assigned to the LSPR mode of Au NPs was detected. Figure S3 shows the UV-vis extinction spectra from an aqueous suspension containing $\mathrm{Au}$ NPs illustrating the $\mathrm{Au}$ LSPR band position around $530 \mathrm{~nm}$. Therefore, it can be stated that this material displays two LSPR bands that can be excited or harvested for photocatalysis: (i) the LSPR excitation of the $\mathrm{MoO}_{3-x}$ supports and (ii) the LSPR excitation of the catalytic Au NPs. To probe the effect of the LSPR excitation from both $\mathrm{Au}$ NPs and $\mathrm{MoO}_{3} \mathrm{P}$ supports, the photocurrent responses for $\mathrm{MoO}_{3} \mathrm{P}$ and $\overline{\mathrm{Au}} / \mathrm{MoO}_{3} \mathrm{P}$ materials in the photoelectrochemical hydrogen evolution reaction were measured. Figure S4A shows the chopped light (light/dark) linear sweep voltammetry for the samples obtained by recording on-off $j-t$ transients under 533 and $650 \mathrm{~nm}$ irradiation. Both $\mathrm{MoO}_{3} \mathrm{P}$ and $\mathrm{Au} / \mathrm{MoO}_{3} \mathrm{P}$ showed a fast and reproducible response to the on-off cycles under both wavelengths. However, the highest photocurrents were detected at $533 \mathrm{~nm}$ irradiation relative to $650 \mathrm{~nm}$. Figure $\mathrm{S} 4 \mathrm{~B}$ shows the Nyquist plot for the $\mathrm{Au} / \mathrm{MoO}_{3} \mathrm{P}$ sample. The Nyquist plot presented one semicircle, and its diameter is equivalent to the charge transfer resistance $\left(R_{\mathrm{ct}}\right)$. Here, $\mathrm{Au} /$ $\mathrm{MoO}_{3} \mathrm{P}$ showed a remarkable decrease of $R_{\mathrm{ct}}$ under light irradiation, starting from $27 \mathrm{~W}_{\mathrm{cm}}{ }^{2}$ in the dark and reaching 17 and $11 \mathrm{~W}_{\mathrm{cm}}^{2}$ for 650 and $533 \mathrm{~nm}$, respectively. This decrease indicates that the most efficient interfacial electron transfer was reached under $533 \mathrm{~nm}$ excitation, which better matches the LSPR band position of $\mathrm{Au}$ in the $\mathrm{Au} / \mathrm{MoO}_{3} \mathrm{P}$ material (Figure 2C).

It has been established that hydrogen intercalation and oxygen vacancies generation play important roles in modifying the electronic and optical properties of $\mathrm{MoO}_{3}$. The $\mathrm{H}^{+}$ intercalation in $\mathrm{MoO}_{3}$ is accompanied by the partial reduction of $\mathrm{Mo}^{6+}$ to $\mathrm{Mo}^{5+}$ and $\mathrm{Mo}^{4+}$ in the substoichiometric lattice $\mathrm{MoO}_{3-x}{ }^{44,51}$ To probe the surface chemistry and associated electronic properties, we carried out an XPS study. Figure $2 \mathrm{D}$, E shows the photoelectron spectra of $\mathrm{MoO}_{3} \mathrm{C}, \mathrm{MoO}_{3} \mathrm{P}$, and $\mathrm{Au} / \mathrm{MoO}_{3} \mathrm{P}$ samples in the Mo 3d (Figure $2 \mathrm{D}$ ) and $\mathrm{O} 1 \mathrm{~s}$ (Figure 2E) core level regions (Figure S5 shows the corresponding XPS survey spectra). The spectrum of the sample $\mathrm{MoO}_{3}$ in the $\mathrm{Mo} 3 \mathrm{~d}$ region can be fitted with two symmetric curves with maxima at binding energy (BE) values of 232.8 and $236.0 \mathrm{eV}$, which correspond well to the Mo $3 \mathrm{~d}_{7 / 2}$ and Mo $3 \mathrm{~d}_{5 / 2}$ doublet for Mo(VI). ${ }^{51,52}$ The fitting of spectra of samples $\mathrm{MoO}_{3} \mathrm{P}$ and $\mathrm{Au} / \mathrm{MoO}_{3} \mathrm{P}$ in the $\mathrm{Mo} 3 \mathrm{~d}$ regions requires an additional doublet with maximum $\mathrm{BE}$ values at 231.5 and $234.6 \mathrm{eV}$ that can be ascribed to $\mathrm{Mo}(\mathrm{V})$ species. $^{52}$ As estimated for the peak fit, the $\mathrm{Mo}(\mathrm{VI}) / \mathrm{Mo}(\mathrm{V})$ atomic ratio is around $90 / 10$ in both samples $\mathrm{MoO}_{3} \mathrm{P}$ and $\mathrm{Au} / \mathrm{MoO}_{3} \mathrm{P}$ (Table 1). These results suggest that hydrogen intercalation

Table 1. Atomic Percentages of Mo and O Species Obtained by XPS Analysis

\begin{tabular}{lccccc} 
& \multicolumn{2}{c}{ Mo $3 \mathrm{~d}$ core levels $(\%)$} & & \multicolumn{2}{c}{ O 1s peak (\%) } \\
\cline { 2 - 3 } \cline { 5 - 6 } \multicolumn{1}{c}{ sample } & $\mathrm{Mo}^{6+}$ & $\mathrm{Mo}^{5+}$ & & $\mathrm{Mo}-\mathrm{O}$ & $-\mathrm{OH}$ \\
$\mathrm{MoO}_{3}$ & 100 & & & 71 & 29 \\
$\mathrm{MoO}_{3-} \mathrm{P}$ & 89.6 & 10.4 & & 65 & 35 \\
$\mathrm{Au} / \mathrm{MoO}_{3 \_} \mathrm{P}$ & 89.4 & 10.6 & & 71 & 29 \\
\hline
\end{tabular}

leads to the selective reduction of $\mathrm{Mo}^{6+}$ to $\mathrm{Mo}^{5+}$. Moreover, the presence of $\mathrm{Mo}^{5+}$ states originated from morphology defects such as oxygen vacancies created during the mechanochemical process, ${ }^{44}$ which seems not to be affected by the presence of $\mathrm{Au}$.

Regarding the $\mathrm{O}$ 1s photoemission peaks, it can be observed in Figure 2E that for all the samples the $\mathrm{O} 1 \mathrm{~s}$ spectrum has its maximum near $530.7 \mathrm{eV}$ and a slight shoulder on the high energy side of the peak. The $\mathrm{O} 1 \mathrm{~s}$ region was fitted in two spectral contributions with maxima at binding energy (BE) values of 530.7 and $531.4 \mathrm{eV}$, which are assigned to $\mathrm{Mo}-\mathrm{O}$ bond and hydroxyl groups $(-\mathrm{OH})$, respectively. ${ }^{51,53}$ The relative amounts of the oxygen species as estimated by peak fit are listed in Table 1. The atomic ratio $\mathrm{O}_{2} / \mathrm{OH}$ is around $70 / 30$ for all the samples. Noticeably, there is a slight increase in the full width at half-maximum (fwhm) on the $\mathrm{O}$ 1s spectra for the $\mathrm{MoO}_{3} \mathrm{P}$ sample, suggesting a higher proportion of hydroxyl groups $(\sim 35 \%)$. A correlation between the presence of $\mathrm{Mo}^{5+}$ and $-\mathrm{OH}$ has been proposed in reduced $\mathrm{MoO}_{3}$, suggesting that large quantities of $\mathrm{Mo}^{5+}$ are accompanied by only very small amounts of $\mathrm{OH}$ groups. ${ }^{53}$ This observation leads us to propose that in our samples the presence of higher amounts of $\mathrm{OH}$ groups could be related to residual $-\mathrm{OH}$ species, which can be originated from the byproducts from the oxidation of $\mathrm{NaBH}_{4}$ or from other oxygen adsorbed species on the particle surface, such as from the dissociative adsorption of $\mathrm{O}_{2}$ onto oxygen vacancies after the washing procedure. ${ }^{54-56}$ The XPS spectrum for the $\mathrm{Au} / \mathrm{MoO}_{3} \mathrm{P}$ sample in the $\mathrm{Au}$ 4f region (Figure 2F) shows two intense photoelectron peaks with maximum binding energy (BE) values of 84.0 and $87.7 \mathrm{eV}$ ascribed to the $\mathrm{Au} 4 \mathrm{f}_{7 / 2}$ and $4 \mathrm{f}_{5 / 2}$ doublet, respectively. These $\mathrm{BE}$ values are characteristic of $\mathrm{Au}$ species in the metallic state, ${ }^{57}$ validating the efficiency of the one-pot mechanochemical approach to reduce both commercial $\mathrm{MoO}_{3}$ and $\mathrm{AuCl}$ precursors.

The electronic properties of the samples were further studied by valence band spectra (Figure 2G). The valence band (VB) of $\mathrm{MoO}_{3}$ consists mainly of $\mathrm{O} 2 \mathrm{p}$ states with contributions from Mo $4 \mathrm{~d}$ due to a certain level of hybridization. The onset of the main VB spectrum for all samples is located around $3 \mathrm{eV}$, and Mo $4 \mathrm{~d}$ states are adjacent to the Fermi level $(0 \mathrm{eV}) .^{51,58,59}$ For the $\mathrm{MoO}_{3} \mathrm{C}$ sample (black trace), the spectrum shows a broad and low intensity feature close to the Fermi level centered at $1.1 \mathrm{eV}$. The $\mathrm{MoO}_{3}$ P sample (blue trace) exhibited a similar spectrum with increased intensity and a new broad feature at higher $\mathrm{BE}$ in the 1.5-2 eV range. Remarkably, for the $\mathrm{Au} / \mathrm{MoO}_{3} \mathrm{P}$ sample (red 
trace), a new shoulder appears around $2.5 \mathrm{eV}$ in addition to this band at $1.5-2 \mathrm{eV}$. These bands observed for the samples after milling with $\mathrm{NaBH}_{4}$ could indicate a partially occupied Mo 4d band within the $\mathrm{MoO}_{3}$ band gap, forming gap states. $^{58,59}$ These gap states act as n-type dopants and push the $\mathrm{MoO}_{3}$ Fermi level very close to the conduction band minimum, originating the signal that was detected at $1.1 \mathrm{eV}$. The appearance of the gap states at $2.2 \mathrm{eV} \mathrm{BE}$ for the $\mathrm{Au} /$ $\mathrm{MoO}_{3} \mathrm{P}$ sample derive from an overlap with $\mathrm{Au} 5 \mathrm{~d}$ and $\mathrm{Au} 6 \mathrm{~s}$ orbitals, which are very close to the Fermi level. ${ }^{58}$ These results suggest that the hydrogen intercalation and consequently the creation of oxygen vacancies promotes the charge carrier's concentration in the conduction band of the $\mathrm{MoO}_{3}$, modifying the optical response of the oxide and enabling LSPR in the visible and near-IR ranges.

The photoluminescence spectra recorded at room temperature for $\mathrm{MoO}_{3} \mathrm{P}$ and $\mathrm{Au} / \mathrm{MoO}_{3} \mathrm{P}$ (Figure S6) support these observations. The PL spectra for both samples displayed PL emission peaks in the $400-620 \mathrm{~nm}$ region. The peak around $425 \mathrm{~nm}$ was attributed to the radiative recombination of interband excitons in crystalline $\mathrm{MoO}_{3}$, which can be shifted as a function of the size and shape of the nanomaterials. ${ }^{60,61}$ The presence of multiple lower energy bands can be assigned to defect emission, mainly due to oxygen vacancies, and the intervalence charge transfer transitions. ${ }^{62-64}$ Finally, there was a decrease in the PL intensity for the $\mathrm{Au} / \mathrm{MoO}_{3} \mathrm{P}$ sample as compared to $\mathrm{MoO}_{3} \mathrm{P}$, indicating that the presence of $\mathrm{Au}$ improves electron-hole separation and suppresses the fluorescence-associated recombination. ${ }^{65}$

We then investigate the morphological features associated with the ball-milling process and the formation of the $\mathrm{Au} /$ $\mathrm{MoO}_{3} \mathrm{P}$ sample. While $\mathrm{MoO}_{3} \mathrm{C}$ displayed a layered, platelike morphology with micrometric sizes assigned to orthorhombic $\alpha-\mathrm{MoO}_{3}$, ball milling led to the reduction of the sizes yielding a heterogeneous size distribution of microplates and irregular particles (Figure S7). This suggests that the mechanochemical process alone causes the disruption of the layered morphology into smaller plates. Interestingly, when the ball milling was carried out in the presence of $\mathrm{NaBH}_{4}$, it could significantly modify the size and the morphology of the particles leading to nanosheets with average sizes around $100 \mathrm{~nm}$ (Figure S7). Here, it is plausible that the intercalated $\mathrm{H}^{+}$ions within the van der Waals gaps can contribute to the partial exfoliation of the layered $\mathrm{MoO}_{3}$, resulting in $2 \mathrm{D}$ morphologies with larger surface areas and making it attractive not only from the point of view of optical properties as illustrated in Figure 2C, but also as a support for photocatalytic applications. ${ }^{66}$

Figure 3A shows the SEM and TEM (inset) images of the $\mathrm{Au} / \mathrm{MoO}_{3} \mathrm{P}$ NPs. SEM and TEM data confirm the presence of the $\mathrm{MoO}_{3}$ nanosheets containing well-dispersed and uniformly distributed $\mathrm{Au}$ NPs over their surface. No significant agglomeration of Au NPs was detected, and the average Au NP size was around $5 \mathrm{~nm}$ (Figure 3B shows a histogram of size distribution). The $\mathrm{Au}$ loading in the $\mathrm{Au} / \mathrm{MoO}_{3} \mathrm{P}$ NPs corresponded to $4.8 \mathrm{wt} \%$ as determined by atomic emission spectroscopy (AES). These results indicate that ball milling enables the hydrogen intercalation in the layered structure generating molybdenum oxide nanosheets displaying optical extinction in the visible and near-infrared ranges and that can act as supports for the uniform deposition of sub-10 nm Au NPs at their surface, which are attractive features for catalysis and photocatalysis.
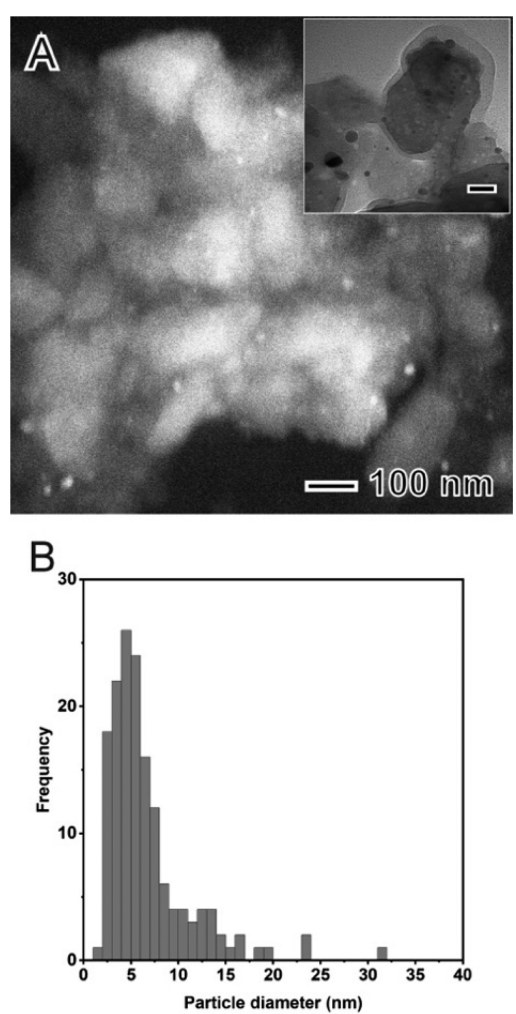

Figure 3. (A) SEM and TEM (inset) images and (B) histogram of the size distribution for Au NPs supported on plasmonic $\mathrm{MoO}_{3}$ produced by ball milling $\mathrm{MoO}_{3}$ and $\mathrm{AuCl}$ in the presence of $\mathrm{NaBH}_{4}(\mathrm{Au} /$ $\mathrm{MoO}_{3} \mathrm{P}$ ). The scale bar in the inset corresponds to $10 \mathrm{~nm}$.

After the successful one-pot, room condition, gram-scale mechanosynthesis of Au NPs supported on plasmonic $\mathrm{MoO}_{3}$, we turned our attention to the plasmonic catalytic activities. We employed the reductive coupling of nitrobenzene to azoxybenzene by transfer hydrogenation as a model reaction. ${ }^{67-69}$ These studies were carried out in the presence of isopropyl alcohol (IPA) and potassium hydroxide (KOH) under an inert atmosphere. It has been shown that $\mathrm{KOH}$ enhances the abstraction of a hydrogen atom from IPA, facilitating the reduction process. ${ }^{68}$ It is well-established that this reaction is catalyzed by $\mathrm{Au}$ NPs and not by the $\mathrm{MoO}_{3}$ plasmonic supports. ${ }^{70-72}$ Therefore, it serves as an excellent proof of concept transformation to investigate the effect of plasmonic excitation of the supports $\left(\mathrm{MoO}_{3} \mathrm{P}\right.$, antenna), of the catalytic component ( $\mathrm{Au}$, catalytic reactor), or both over the photocatalytic properties. Here, it is expected that the surface of the catalyst is comprised of Au NPs (serving as the active phase) and the $\mathrm{MoO}_{3}$ material, acting as a support. The surface area as determined by $\mathrm{BET}$ for $\mathrm{MoO}_{3} \mathrm{P}$ and $\mathrm{Au} /$ $\mathrm{MoO}_{3} \mathrm{P}$ materials that were employed as catalysts corresponded to 11.2661 and $10.6367 \mathrm{~m}^{2} / \mathrm{g}$, respectively. This result indicates that the deposition of Au NPs led to a small decrease in the surface area $(5.6 \%)$. It is plausible that this occurred due to the blocking of the $\mathrm{MoO}_{3}$ surface upon $\mathrm{Au}$ deposition. Regarding the light irradiation wavelengths, we employed 530 and $740 \mathrm{~nm}$ to match the LSPR of Au NPs and $\mathrm{MoO}_{3} \mathrm{P}$, respectively. For the experiment under light excitation (light on), the reactor was irradiated by using four Kessil PR 160 LEDs with 530 and/or $740 \mathrm{~nm}$ irradiation at a reactor-lamp distance of $6 \mathrm{~cm}$ having a total irradiance of $14.34 \mathrm{~mW} / \mathrm{cm}^{-2}$ and a cooling fan positioned above the 
reaction flask. For the experiment employing two different wavelengths, the reactor was irradiated by using two $740 \mathrm{~nm}$ and two $530 \mathrm{~nm}$ LEDs having the same irradiance as described above.

We started by investigating the activity of the plasmonic $\mathrm{MoO}_{3} \mathrm{P}$ supports, which did not display any detectable conversion percent under the employed conditions under both wavelengths (Table 2, entries 1 and 2). This confirms that the

Table 2. Conversion and Selectivity for the Hydrogenation of Nitrobenzene to Azobenzene as a Function of the Catalyst and Reaction Conditions ${ }^{a}$<smiles>O=[N+]([O-])c1ccccc1</smiles>

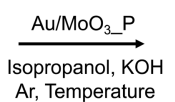

Nitrobenzene

\begin{tabular}{|c|c|c|c|c|c|c|}
\hline & & \multicolumn{2}{|c|}{ 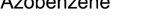 } \\
\hline \multirow[b]{2}{*}{ entry } & \multirow[b]{2}{*}{ catalyst } & \multirow[b]{2}{*}{ light source $(\mathrm{nm})$} & \multicolumn{2}{|c|}{$\begin{array}{c}\text { conversion } \\
(\%)\end{array}$} & \multicolumn{2}{|c|}{$\begin{array}{c}\text { selectivity } \\
(\%)\end{array}$} \\
\hline & & & dark & light & dark & $\overline{\text { light }}$ \\
\hline 1 & $\mathrm{MoO}_{3 \_} \mathrm{P}$ & 530 & 0 & 0 & 0 & 0 \\
\hline 2 & $\mathrm{MoO}_{3 \_} \mathrm{P}$ & 740 & 0 & 0 & 0 & 0 \\
\hline 3 & $\mathrm{Au} / \mathrm{MoO}_{3}{ }_{-} \mathrm{P}$ & 530 & 46 & 52 & 95 & 96 \\
\hline 4 & $\mathrm{Au} / \mathrm{MoO}_{3}{ }_{-} \mathrm{P}$ & 740 & 46 & 80 & 95 & 96 \\
\hline 5 & $\mathrm{Au} / \mathrm{MoO}_{3}{ }_{-} \mathrm{P}$ & $530+740$ & & 100 & & 96 \\
\hline
\end{tabular}

${ }^{a_{\text {The }}}$ reactions were conducted under Ar atmosphere ( $\left.1 \mathrm{~atm}\right), 5 \mathrm{~mL}$ of isopropanol, $0.15 \mathrm{mmol}$ of $\mathrm{KOH}, 1.5 \mathrm{mmol}$ of substrate, and $30 \mathrm{mg}$ of catalyst. The reaction time was $6 \mathrm{~h}$.

$\mathrm{MoO}_{3} \mathrm{P}$ supports do not show activity toward this transformation. The $\mathrm{Au} / \mathrm{MoO}_{3} \mathrm{P}$ sample displayed $46 \%$ conversion of nitrobenzene with $95 \%$ selectivity toward the azobenzene product under dark conditions (Table 2, entries 3 and 4). The activity in the dark for $\mathrm{Au} / \mathrm{MoO}_{3} \mathrm{P}$ is due to the catalytic activity of Au NPs toward this transformation. ${ }^{70-72}$ Here, the use of $\mathrm{KOH}$ favors the abstraction of a hydrogen atom from IPA, leading to $\mathrm{Au}-\mathrm{H}$ species at the surface. These species can combine with oxygen atoms of the $\mathrm{N}-\mathrm{O}$ bonds and subsequently lead to the cleavage of the $\mathrm{N}-\mathrm{O}$ bond, which is the key step of the reduction reaction. ${ }^{68}$

Surprisingly, under green light irradiation, the nitrobenzene conversion was $52 \%$ with $96 \%$ selectivity (Table 2 , entry 3 ).
This indicated that the LSPR excitation on Au NPs leads to no significant increase in the catalytic activity. However, when the sample was irradiated at $740 \mathrm{~nm}$, near the plasmonic excitation of the $\mathrm{MoO}_{3} \mathrm{P}$ supports acting as antennas, a significant increase in the nitrobenzene conversion to $80 \%$ was observed (96\% selectivity for azobenzene, Table 2, entry 4). This increase in activity can be explained by the excitation of the plasmonic molybdenum oxide yielding energetic hot carriers that can be transferred to the Au NPs at the interface and contribute to vibrational or electronic activation of adsorbed molecules. This observation suggests that the excitation of the $\mathrm{MoO}_{3} \mathrm{P}$ LSPR was effective to enhance the catalytic performance of the $\mathrm{Au} / \mathrm{MoO}_{3} \mathrm{P}$ sample, while the excitation of the Au LSPR was not.

Finally, we wanted to investigate the effect of dual LSPR excitation, i.e., excitation of the LSPR of both $\mathrm{MoO}_{3} \mathrm{P}$ and $\mathrm{Au}$ NPs. To achieve this, we employed two different wavelengths (525 and $740 \mathrm{~nm}$ ) while keeping the overall illumination power constant. Surprisingly, the dual plasmonic excitation led to an increase in the nitrobenzene conversion to $100 \%$ (96\% selectivity to azobenzene, Table 2 , entry 5 ). This result shows a synergistic effect when both the plasmonic antenna and reactor are excited. Interestingly, this indicates that dual plasmonic excitation can open new avenues for the optimization of plasmonic photocatalytic performances when both support (antenna) and plasmonic NPs (reactor) support LSPR excitation. This enhancement in conversion percent also increased as a function of temperature as shown in Figure S8. Although a direct comparison is challenging due to the utilization of distinct experimental parameters, light excitation sources, and illumination powers, the plasmonic catalytic performances for the $\mathrm{Au} / \mathrm{MoO}_{3} \mathrm{P}$ materials reported here are comparable to those of other plasmonic catalysts reported in the literature (Table S1). Figure S9A shows the stability studies under plasmonic excitation for $\mathrm{Au} / \mathrm{MoO}_{3} \mathrm{P}$ catalysts. After each reaction cycle, the $\mathrm{Au} / \mathrm{MoO}_{3} \mathrm{P}$ catalysts were isolated from the reaction mixture by centrifugation and washed before being reused in the next reaction cycle. It can be observed that there was a loss of plasmonic catalytic activity after each cycle. The loss of activity may be related to morphological changes on both $\mathrm{Au}$ NPs and $\mathrm{MoO}_{3} \mathrm{P}$ supports that occur in the catalysts as illustrated by SEM images after the third reaction cycle (Figure S9B). These

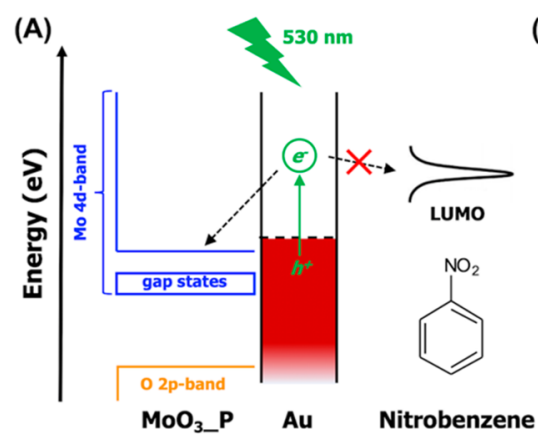

(B)

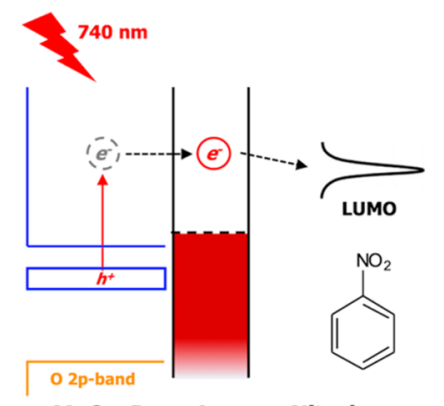

$\mathrm{MoO}_{3} \mathbf{P}$ Au Nitrobenzene
(C)

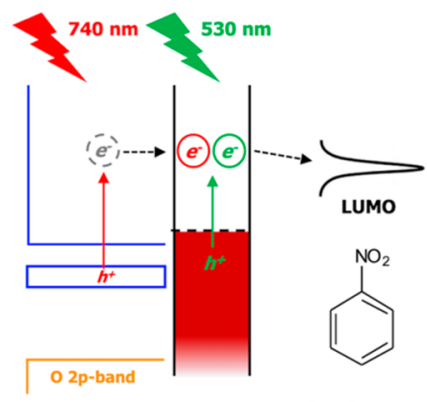

$\mathrm{MoO}_{3} \mathbf{P}$ Au Nitrobenzene

Figure 4. Energy level diagrams and proposed mechanism for activation of adsorbed nitrobenzene over $\mathrm{Au} / \mathrm{MoO}_{3}$ P NPs. (A) Illumination at 530 $\mathrm{nm}$ leads to the excitation of the LSPR in Au NPs. The LSPR-excited hot electrons from $\mathrm{Au}$ are injected into the conduction band of $\mathrm{MoO}_{3}$, not being available for vibrational or electronic activation of adsorbed nitrobenzene. (B) Illumination at $740 \mathrm{~nm}$ leads to the excitation of the LSPR in $\mathrm{MoO}_{3}$. LSPR-excited hot electrons from gap states in the Mo $4 \mathrm{~d}$ band can be transferred to Au, where they contribute to the activation of nitrobenzene, leading to an increase in the reaction rate. (C) Illumination under both 530 and $740 \mathrm{~nm}$ leads to the LSPR excitation of Au NPs and $\mathrm{MoO}_{3}$. In addition to LSPR-excited hot electrons from $\mathrm{MoO}_{3}$, LSPR-excited hot electrons are also generated on Au, and both can participate in the surface activation of nitrobenzene. 
results indicate the stability under plasmonic catalytic conditions for the $\mathrm{Au} / \mathrm{MoO}_{3} \mathrm{P}$ materials needs further optimizations.

A proposed mechanism for the observed catalytic performance is shown in Figure 4. When $525 \mathrm{~nm}$ is employed to excite the LSPR of Au NPs, hot electrons generated from the LSPR excitation in $\mathrm{Au}$ can activate the chemisorbed nitrobenzene molecule or be transferred to the $\mathrm{MoO}_{3}$ conduction band, which is located below the Fermi level for Au (Figure 4A). ${ }^{58}$ Our data, which show no enhancement in catalytic activity under $525 \mathrm{~nm}$ excitation, suggests that the latter process is predominant in this case. Therefore, hot electrons are injected into the $\mathrm{MoO}_{3}$ conduction band and do not activate adsorbed nitrobenzene molecules, leading to no enhancement in conversion percent under $525 \mathrm{~nm}$ relative to dark conditions. Conversely, when $740 \mathrm{~nm}$ is employed as the light excitation wavelength, we hypothesize that the hot electrons generated in the conduction band of $\mathrm{MoO}_{3}$ from its LSPR excitation can be transferred to $\mathrm{Au}$ NPs, wherein they can subsequently activate adsorbed nitrobenzene molecules and accelerate the reaction (Figure 4B). This agrees with the several examples of reported catalytic enhancements due to the LSPR excitation in antenna-reactor nanoparticle designs. ${ }^{36,38,41}$ Finally, when 525 and $740 \mathrm{~nm}$ are employed to excite both the $\mathrm{Au}$ and $\mathrm{MoO}_{3} \mathrm{P}$, respectively, hot charges are generated at both $\mathrm{Au}$ NPs and $\mathrm{MoO}_{3} \mathrm{P}$ (Figure $4 \mathrm{C}$ ). Here, it is plausible that the LSPR hot carriers generated in $\mathrm{MoO}_{3} \mathrm{P}$ can flow to Au NPs as indicated by the enhancements detected under $740 \mathrm{~nm}$ excitation. These charge carriers, together with the hot charges generated from the LSPR excitation in $\mathrm{Au}$, contribute to increasing the density of hot carriers at Au NPs because of the dual LSPR excitation. Therefore, this can contribute to a more effective activation of adsorbed nitrobenzene molecules and therefore lead to a further increase in catalytic activity under light irradiation.

\section{CONCLUSIONS}

We reported herein on a mechanochemical approach for the one-pot, gram-scale, room condition, $1 \mathrm{~h}$ synthesis of plasmonic photocatalysts comprised of Au NPs supported on $\mathrm{MoO}_{3}$ supports in an antenna-reactor nanoparticle design. Importantly, in this system, both the $\mathrm{MoO}_{3}$ supports (antenna) and Au NPs (catalytic reactor) support LSPR excitation in the visible range. The synthesis of plasmonic $\mathrm{MoO}_{3}$ supports took place via hydrogen intercalation during the ball-milling process, which was generated from $\mathrm{NaBH}_{4}$ that was also employed as a reducing agent to generate the Au NPs from $\mathrm{Au}(\mathrm{I})$. Our spectroscopic data showed that this process was effective and that the $\mathrm{MoO}_{3}$ supports displayed strong LSPR signals in the visible range. Interestingly, these unique antenna-reactor plasmonic photocatalysts allowed study on the effect of dual plasmonic excitation, i.e., the excitation of the LSPR bands of both the support (antenna) and Au NPs (reactor) relative to the LSPR excitation of only $\mathrm{Au}$ NPs or $\mathrm{MoO}_{3}$ supports over the plasmonic photocatalytic activity. Intriguingly, it was found that the dual LSPR excitation of both $\mathrm{Au}$ NPs and $\mathrm{MoO}_{3}$ supports enabled a synergic enhancement of the catalytic activity toward the reductive coupling of nitrobenzene to azobenzene relative to dark conditions and excitation of either $\mathrm{Au}$ NPs or $\mathrm{MoO}_{3}$ LSPR. A mechanism based on the combination of the generation of LSPR-excited charge carriers in Au NPs and energy from LSPR-excited charge carriers from $\mathrm{MoO}_{3}$ to $\mathrm{Au}$ was proposed to account for the detected photocatalytic performance. We believe that the results reported herein may provide a pathway to the facile and gram-scale synthesis of plasmonic photocatalysts and open novel pathways as well as provide new design principles to plasmonic photocatalysts displaying improved activities to enable more sustainable molecular transformations.

\section{ASSOCIATED CONTENT}

\section{Supporting Information}

The Supporting Information is available free of charge at https://pubs.acs.org/doi/10.1021/acssuschemeng.1c02063.

Characterization of $\mathrm{Au} / \mathrm{MoO}_{3}$ materials by XRD, SEM, photoluminescence, $\mathrm{H}_{2}$-TPD, photocurrent, and $\mathrm{Ny}$ quist plots; catalytic performance as a function of reaction temperature; stability tests (PDF)

\section{AUTHOR INFORMATION}

\section{Corresponding Author}

Pedro H. C. Camargo - Department of Chemistry, University of Helsinki, 00560 Helsinki, Finland; (1) orcid.org/00000002-7815-7919; Email: pedro.camargo@helsinki.fi

\section{Authors}

Jhon Quiroz - Department of Chemistry, University of Helsinki, 00560 Helsinki, Finland

Paulo F. M. de Oliveira - Departamento de Química Fundamental, Instituto de Química, Universidade de São Paulo, 05508000 São Paulo, Brazil; BAM Federal Institute for Materials Research and Testing, 12489 Berlin, Germany; (1) orcid.org/0000-0003-4854-5352

Shwetha Shetty - Department of Chemistry, University of Helsinki, 00560 Helsinki, Finland

Freddy E. Oropeza - Photoactivated Processes Unit, IMDEA Energy Institute, 28935 Mostoles, Madrid, Spain; (1) orcid.org/0000-0001-7222-9603

Víctor A. de la Peña O'Shea - Photoactivated Processes Unit, IMDEA Energy Institute, 28935 Mostoles, Madrid, Spain; (1) orcid.org/0000-0001-5762-4787

Lucas C. V. Rodrigues - Departamento de Química Fundamental, Instituto de Química, Universidade de São Paulo, 05508000 São Paulo, Brazil; (1) orcid.org/00000001-5176-5001

Maria P. de S. Rodrigues - Departamento de Química Fundamental, Instituto de Química, Universidade de São Paulo, 05508000 São Paulo, Brazil

Roberto Manuel Torresi - Departamento de Química Fundamental, Instituto de Química, Universidade de São Paulo, 05508000 São Paulo, Brazil; (1) orcid.org/00000003-4414-5431

Franziska Emmerling - BAM Federal Institute for Materials Research and Testing, 12489 Berlin, Germany; 이이.org/ 0000-0001-8528-0301

Complete contact information is available at:

https://pubs.acs.org/10.1021/acssuschemeng.1c02063

\section{Author Contributions}

${ }^{\perp}$ J.Q. and P.F.M.O.: These authors contributed equally to this work.

\section{Notes}

The authors declare no competing financial interest. 


\section{ACKNOWLEDGMENTS}

This work was supported by the Jane and Aatos Erkko Foundation, startup funds from the University of Helsinki, Academy of Finland, and seed funding from the Helsinki Institute of Sustainability Science (HELSUS). P.F.M.O and R.M.T. thank FAPESP (Grants 2017/15456-0, 2019/01619-0, and 2015/26308-7). This work was supported by the Spanish AEI-MINECO (PID2019-106315RB-I00). The authors also wish to thank Comunidad de Madrid and European Structural Funds for their financial support for the FotoArt-CM project (S2018/NMT-4367) and Fundación Ramón Areces. We thank Dr. Adriano H. Braga and Prof. Liane M. Rossi for their help with the $\mathrm{H}_{2}$-TPD analysis and Prof. Susana I. C. de Torresi for the electrochemistry setup.

\section{REFERENCES}

(1) James, S. L.; Adams, C. J.; Bolm, C.; Braga, D.; Collier, P.; Friščć, T.; Grepioni, F.; Harris, K. D. M.; Hyett, G.; Jones, W.; et al. Mechanochemistry: Opportunities for New and Cleaner Synthesis. Chem. Soc. Rev. 2012, 41 (1), 413-447.

(2) Lin, L.; Wang, K.; Azmi, R.; Wang, J.; Sarkar, A.; Botros, M.; Najib, S.; Cui, Y.; Stenzel, D.; Anitha Sukkurji, P.; et al. Mechanochemical Synthesis: Route to Novel Rock-Salt-Structured High-Entropy Oxides and Oxyfluorides. J. Mater. Sci. 2020, 55, 16879-16889.

(3) Šepelák, V.; Düvel, A.; Wilkening, M.; Becker, K. D.; Heitjans, P. Mechanochemical Reactions and Syntheses of Oxides. Chem. Soc. Rev. 2013, 42 (18), 7507-7520.

(4) Ralphs, K.; Hardacre, C.; James, S. L. Application of Heterogeneous Catalysts Prepared by Mechanochemical Synthesis. Chem. Soc. Rev. 2013, 42 (18), 7701-7718.

(5) Šepelák, V.; Bégin-Colin, S.; Le Caër, G. Transformations in Oxides Induced by High-Energy Ball-Milling. Dalton Transactions 2012, 41 (39), 11927-11948.

(6) Bai, S.; Zhang, N.; Gao, C.; Xiong, Y. Defect Engineering in Photocatalytic Materials. Nano Energy 2018, 53, 296-336.

(7) De Oliveira, P. F. M.; Torresi, R. M.; Emmerling, F.; Camargo, P. H. C. Challenges and Opportunities in the Bottom-up Mechanochemical Synthesis of Noble Metal Nanoparticles. J. Mater. Chem. A 2020, 8 (32), 16114-16141.

(8) Rak, M. J.; Saadé, N. K.; Frǐ̌číć, T.; Moores, A. Mechanosynthesis of Ultra-Small Monodisperse Amine-Stabilized Gold Nanoparticles with Controllable Size. Green Chem. 2014, 16 (1), 86-89.

(9) Rak, M. J.; Friščíc, T.; Moores, A. Mechanochemical Synthesis of $\mathrm{Au}, \mathrm{Pd}, \mathrm{Ru}$ and Re Nanoparticles with Lignin as a Bio-Based Reducing Agent and Stabilizing Matrix. Faraday Discuss. 2014, 170 (514), 155167.

(10) Fiss, B. G.; Vu, N. N.; Douglas, G.; Do, T. O.; Friščić, T.; Moores, A. Solvent-Free Mechanochemical Synthesis of Ultrasmall Nickel Phosphide Nanoparticles and Their Application as a Catalyst for the Hydrogen Evolution Reaction (HER). ACS Sustainable Chem. Eng. 2020, 8 (32), 12014-12024.

(11) de Oliveira, P. F. M.; Quiroz, J.; de Oliveira, D. C.; Camargo, P. H. C. A Mechano-Colloidal Approach for the Controlled Synthesis of Metal Nanoparticles. Chem. Commun. 2019, 55 (95), 14267-14270.

(12) De Oliveira, P. F. M.; Michalchuk, A. A. L.; Marquardt, J.; Feiler, T.; Prinz, C.; Torresi, R. M.; Camargo, P. H. C.; Emmerling, F. Investigating the Role of Reducing Agents on Mechanosynthesis of Au Nanoparticles. CrystEngComm 2020, 22 (38), 6261-6267.

(13) Song, J.; Huang, P.; Duan, H.; Chen, X. Plasmonic Vesicles of Amphiphilic Nanocrystals: Optically Active Multifunctional Platform for Cancer Diagnosis and Therapy. Acc. Chem. Res. 2015, 48 (9), 2506-2515.

(14) White, R. J.; Luque, R.; Budarin, V. L.; Clark, J. H.; Macquarrie, D. J. Supported Metal Nanoparticles on Porous Materials. Methods and Applications. Chem. Soc. Rev. 2009, 38 (2), 481-494.
(15) Lanzafame, P.; Perathoner, S.; Centi, G.; Gross, S.; Hensen, E. J. M. Grand Challenges for Catalysis in the Science and Technology Roadmap on Catalysis for Europe: Moving Ahead for a Sustainable Future. Catal. Sci. Technol. 2017, 7 (22), 5182-5194.

(16) Linic, S.; Aslam, U.; Boerigter, C.; Morabito, M. Photochemical Transformations on Plasmonic Metal Nanoparticles. Nat. Mater. 2015, 14 (6), 567-576.

(17) Jiang, N.; Zhuo, X.; Wang, J. Active Plasmonics: Principles, Structures, and Applications. Chem. Rev. 2018, 118 (6), 3054-3099.

(18) Zhang, Y.; He, S.; Guo, W.; Hu, Y.; Huang, J.; Mulcahy, J. R.; Wei, W. D. Surface-Plasmon-Driven Hot Electron Photochemistry. Chem. Rev. 2018, 118 (6), 2927-2954.

(19) Aslam, U.; Rao, V. G.; Chavez, S.; Linic, S. Catalytic Conversion of Solar to Chemical Energy on Plasmonic Metal Nanostructures. Nat. Catal. 2018, 1 (9), 656-665.

(20) Zhou, L.; Martirez, J. M. P.; Finzel, J.; Zhang, C.; Swearer, D. F.; Tian, S.; Robatjazi, H.; Lou, M.; Dong, L.; Henderson, L.; et al. Light-Driven Methane Dry Reforming with Single Atomic Site Antenna-Reactor Plasmonic Photocatalysts. Nat. Energy 2020, 5, 6170.

(21) Collado, L.; Reynal, A.; Fresno, F.; Barawi, M.; Escudero, C.; Perez-Dieste, V.; Coronado, J. M.; Serrano, D. P.; Durrant, J. R.; de la Peña O'Shea, V. A. Unravelling the Effect of Charge Dynamics at the Plasmonic Metal/Semiconductor Interface for $\mathrm{CO} 2$ Photoreduction. Nat. Commun. 2018, 9 (1), 4986.

(22) Collado, L.; Reynal, A.; Coronado, J. M.; Serrano, D. P.; Durrant, J. R.; De la Peña O'Shea, V. A. Effect of Au Surface Plasmon Nanoparticles on the Selective CO2 Photoreduction to CH4. Appl. Catal., B 2015, 178, 177-185.

(23) Araujo, T. P.; Quiroz, J.; Barbosa, E. C. M.; Camargo, P. H. C. Understanding Plasmonic Catalysis with Controlled Nanomaterials Based on Catalytic and Plasmonic Metals. Curr. Opin. Colloid Interface Sci. 2019, 39, 110-122.

(24) Quiroz, J.; Barbosa, E. C. M.; Araujo, T. P.; Fiorio, J. L.; Wang, Y. C.; Zou, Y. C.; Mou, T.; Alves, T. V.; De Oliveira, D. C.; Wang, B.; et al. Controlling Reaction Selectivity over Hybrid Plasmonic Nanocatalysts. Nano Lett. 2018, 18 (11), 7289-7297.

(25) Brongersma, M. L.; Halas, N. J.; Nordlander, P. PlasmonInduced Hot Carrier Science and Technology. Nat. Nanotechnol. 2015, 10 (1), 25-34.

(26) Christopher, P.; Xin, H.; Marimuthu, A.; Linic, S. Singular Characteristics and Unique Chemical Bond Activation Mechanisms of Photocatalytic Reactions on Plasmonic Nanostructures. Nat. Mater. 2012, 11 (12), 1044-1050.

(27) Zhang, C.; Zhao, H.; Zhou, L.; Schlather, A. E.; Dong, L.; McClain, M. J.; Swearer, D. F.; Nordlander, P.; Halas, N. J. Al-Pd Nanodisk Heterodimers as Antenna-Reactor Photocatalysts. Nano Lett. 2016, 16 (10), 6677-6682.

(28) Swearer, D. F.; Robatjazi, H.; Martirez, J. M. P.; Zhang, M.; Zhou, L.; Carter, E. A.; Nordlander, P.; Halas, N. J. Plasmonic Photocatalysis of Nitrous Oxide into $\mathrm{N}_{2}$ and $\mathrm{O}_{2}$ Using AluminumIridium Antenna-Reactor Nanoparticles. ACS Nano 2019, 13 (7), 8076-8086.

(29) Sterl, F.; Strohfeldt, N.; Walter, R.; Griessen, R.; Tittl, A.; Giessen, H. Magnesium as Novel Material for Active Plasmonics in the Visible Wavelength Range. Nano Lett. 2015, 15 (12), 7949-7955.

(30) Marimuthu, A.; Zhang, J.; Linic, S. Tuning Selectivity in Propylene Epoxidation by Plasmon Mediated Photo-Switching of $\mathrm{Cu}$ Oxidation State. Science 2013, 339 (6127), 1590-1593.

(31) Naik, G. V.; Shalaev, V. M.; Boltasseva, A. Alternative Plasmonic Materials: Beyond Gold and Silver. Adv. Mater. 2013, 25 (24), 3264-3294.

(32) Kriegel, I.; Scotognella, F.; Manna, L. Plasmonic Doped Semiconductor Nanocrystals: Properties, Fabrication, Applications and Perspectives. Phys. Rep. 2017, 674, 1-52.

(33) Ren, H.; Sun, S.; Cui, J.; Li, X. Synthesis, Functional Modifications, and Diversified Applications of Molybdenum Oxides Micro-/Nanocrystals: A Review. Cryst. Growth Des. 2018, 18 (10), 6326-6369. 
(34) Agrawal, A.; Cho, S. H.; Zandi, O.; Ghosh, S.; Johns, R. W.; Milliron, D. J. Localized Surface Plasmon Resonance in Semiconductor Nanocrystals. Chem. Rev. 2018, 118 (6), 3121-3207.

(35) Pradhan, N.; Das Adhikari, S.; Nag, A.; Sarma, D. D. Luminescence, Plasmonic, and Magnetic Properties of Doped Semiconductor Nanocrystals. Angew. Chem., Int. Ed. 2017, 56 (25), $7038-7054$.

(36) Kuwahara, Y.; Yoshimura, Y.; Haematsu, K.; Yamashita, H. Mild Deoxygenation of Sulfoxides over Plasmonic Molybdenum Oxide Hybrid with Dramatic Activity Enhancement under Visible Light. J. Am. Chem. Soc. 2018, 140 (29), 9203-9210.

(37) Cheng, H.; Qian, X.; Kuwahara, Y.; Mori, K.; Yamashita, H. A Plasmonic Molybdenum Oxide Hybrid with Reversible Tunability for Visible-Light-Enhanced Catalytic Reactions. Adv. Mater. 2015, 27 (31), 4616-4621.

(38) Yin, H.; Kuwahara, Y.; Mori, K.; Che, M.; Yamashita, H. Plasmonic $\mathrm{Ru} /$ Hydrogen Molybdenum Bronzes with Tunable Oxygen Vacancies for Light-Driven Reduction of: P -Nitrophenol. J. Mater. Chem. A 2019, 7 (8), 3783-3789.

(39) Yin, Q.; Tan, L.; Lang, Q.; Ke, X.; Bai, L.; Guo, K.; Qiao, R.; Bai, S. Plasmonic Molybdenum Oxide Nanosheets Supported Silver Nanocubes for Enhanced Near-Infrared Antibacterial Activity: Synergism of Photothermal Effect, Silver Release and Photocatalytic Reactions. Appl. Catal., B 2018, 224, 671-680.

(40) Hosseini, M. A.; Ranjbar, M.; Sajadi, M. Au-MoOx Nanoparticles for LSPR Hydrogen Detection Prepared by a Facile Anodizing Method. Phys. Lett. A 2020, 384 (3), 126079.

(41) Wang, Y.; Zhang, X.; Luo, Z.; Huang, X.; Tan, C.; Li, H.; Zheng, B.; Li, B.; Huang, Y.; Yang, J.; et al. Liquid-Phase Growth of Platinum Nanoparticles on Molybdenum Trioxide Nanosheets: An Enhanced Catalyst with Intrinsic Peroxidase-like Catalytic Activity. Nanoscale 2014, 6 (21), 12340-12344.

(42) Brunauer, S.; Emmett, P. H.; Teller, E. Adsorption of Gases in Multimolecular Layers. J. Am. Chem. Soc. 1938, 60, 309-319.

(43) Zhang, B. Y.; Zavabeti, A.; Chrimes, A. F.; Haque, F.; O’Dell, L. A.; Khan, H.; Syed, N.; Datta, R.; Wang, Y.; Chesman, A. S. R.; et al. Degenerately Hydrogen Doped Molybdenum Oxide Nanodisks for Ultrasensitive Plasmonic Biosensing. Adv. Funct. Mater. 2018, 28 (11), 1706006.

(44) Borgschulte, A.; Sambalova, O.; Delmelle, R.; Jenatsch, S.; Hany, R.; Nüesch, F. Hydrogen Reduction of Molybdenum Oxide at Room Temperature. Sci. Rep. 2017, 7, 40761.

(45) Sivak, M. V.; Streletskii, A. N.; Kolbanev, I. V.; Leonov, A. V.; Degtyarev, E. N. Thermal Relaxation of Defects in Nanosized Mechanically Activated MoO3. Colloid J. 2016, 78 (5), 674-684.

(46) Braida, B.; Adams, S.; Canadell, E. Concerning the Structure of Hydrogen Molybdenum Bronze Phase III. A Combined TheoreticalExperimental Study. Chem. Mater. 2005, 17 (24), 5957-5969.

(47) Dickens, P. G.; Birtill, J. J.; Wright, C. J. Elastic and Inelastic Neutron Studies of Hydrogen Molybdenum Bronzes. J. Solid State Chem. 1979, 28 (2), 185-193.

(48) Alsaif, M. M. Y. A.; Chrimes, A. F.; Daeneke, T.; Balendhran, S.; Bellisario, D. O.; Son, Y.; Field, M. R.; Zhang, W.; Nili, H.; Nguyen, E. P.; et al. High-Performance Field Effect Transistors Using Electronic Inks of 2D Molybdenum Oxide Nanoflakes. Adv. Funct. Mater. 2016, 26 (1), 91-100.

(49) Alsaif, M. M. Y. A.; Field, M. R.; Daeneke, T.; Chrimes, A. F.; Zhang, W.; Carey, B. J.; Berean, K. J.; Walia, S.; Van Embden, J.; Zhang, B.; et al. Exfoliation Solvent Dependent Plasmon Resonances in Two-Dimensional Sub-Stoichiometric Molybdenum Oxide Nanoflakes. ACS Appl. Mater. Interfaces 2016, 8 (5), 3482-3493.

(50) Liu, W.; Xu, Q.; Cui, W.; Zhu, C.; Qi, Y. CO2-Assisted Fabrication of Two-Dimensional Amorphous Molybdenum Oxide Nanosheets for Enhanced Plasmon Resonances. Angew. Chem., Int. Ed. 2017, 56 (6), 1600-1604.

(51) Vasilopoulou, M.; Douvas, A. M.; Georgiadou, D. G.; Palilis, L. C.; Kennou, S.; Sygellou, L.; Soultati, A.; Kostis, I.; Papadimitropoulos, G.; Davazoglou, D.; et al. The Influence of Hydrogenation and Oxygen Vacancies on Molybdenum Oxides Work
Function and Gap States for Application in Organic Optoelectronics. J. Am. Chem. Soc. 2012, 134 (39), 16178-16187.

(52) Alsaif, M. M. Y. A.; Latham, K.; Field, M. R.; Yao, D. D.; Medehkar, N. V.; Beane, G. A.; Kaner, R. B.; Russo, S. P.; Ou, J. Z.; Kalantar-Zadeh, K. Tunable Plasmon Resonances in Two-Dimensional Molybdenum Oxide Nanoflakes. Adv. Mater. 2014, 26 (23), 3931-3937.

(53) Fleisch, T. H.; Mains, G. J. An XPS Study of the UV Reduction and Photochromism of MoO3 and WO3. J. Chem. Phys. 1982, 76 (2), $780-786$.

(54) Bielanski, A.; Haber, J. Oxygen in Catalysis on Transition Metal Oxides. Catal. Rev.: Sci. Eng. 1979, 19 (1), 1-41.

(55) Pushkarev, V. V.; Kovalchuk, V. I.; D’Itri, J. L. Probing Defect Sites on the $\mathrm{CeO} 2$ Surface with Dioxygen. J. Phys. Chem. B 2004, 108 (17), 5341-5348.

(56) Yang, Y.; Zhang, S.; Wang, S.; Zhang, K.; Wang, H.; Huang, J.; Deng, S.; Wang, B.; Wang, Y.; Yu, G. Ball Milling Synthesized MnOx as Highly Active Catalyst for Gaseous POPs Removal: Significance of Mechanochemically Induced Oxygen Vacancies. Environ. Sci. Technol. 2015, 49 (7), 4473-4480.

(57) Grunwaldt, J. D.; Kiener, C.; Wögerbauer, C.; Baiker, A. Preparation of Supported Gold Catalysts for Low-Temperature CO Oxidation via "Size-Controlled" Gold Colloids. J. Catal. 1999, 181 (2), 223-232.

(58) Greiner, M. T.; Chai, L.; Helander, M. G.; Tang, W. M.; Lu, Z. H. Metal/Metal-Oxide Interfaces: How Metal Contacts Affect the Work Function and Band Structure of MoO3. Adv. Funct. Mater. 2013, 23 (2), 215-226.

(59) Greiner, M. T.; Helander, M. G.; Tang, W. M.; Wang, Z.-B.; Qiu, J.; Lu, Z. H. Universal Energy-Level Alignment of Molecules on Metal Oxides. Nat. Mater. 2012, 11 (1), 76-81.

(60) Song, L. X.; Xia, J.; Dang, Z.; Yang, J.; Wang, L. B.; Chen, J. Formation, Structure and Physical Properties of a Series of $\alpha-\mathrm{MoO} 3$ Nanocrystals: From 3D to 1D and 2D. CrystEngComm 2012, 14 (8), 2675-2682.

(61) Hu, X. K.; Qian, Y. T.; Song, Z. T.; Huang, J. R.; Cao, R.; Xiao, J. Q. Comparative Study on $\mathrm{MoO} 3$ and $\mathrm{HxMoO} 3$ Nanobelts: Structure and Electric Transport. Chem. Mater. 2008, 20 (4), 15271533.

(62) Boukhachem, A.; Kamoun, O.; Mrabet, C.; Mannai, C.; Zouaghi, N.; Yumak, A.; Boubaker, K.; Amlouk, M. Structural, Optical, Vibrational and Photoluminescence Studies of Sn-Doped MoO3 Sprayed Thin Films. Mater. Res. Bull. 2015, 72, 252-263.

(63) Chen, X.; Lei, W.; Liu, D.; Hao, J.; Cui, Q.; Zou, G. Synthesis and Characterization of Hexagonal and Truncated Hexagonal Shaped MoO3 Nanoplates. J. Phys. Chem. C 2009, 113 (52), 21582-21585.

(64) Chen, Y.; Wang, B. Effects of Deposition Parameters on Structures and Photoluminescence of MoO3-x Nanomaterials Grown by CVD. Opt. Mater. 2019, 92, 150-155.

(65) Liu, W.; Tian, Q.; Yang, J.; Zhou, Y.; Chang, H.; Cui, W.; Xu, Q. A Two-Dimensional Amorphous Plasmonic Heterostructure of $\mathrm{Pd} / \mathrm{MoO} 3-\mathrm{x}$ for Enhanced Photoelectrochemical Water Splitting Performance. Chem. - Asian J. 2021, 16 (10), 1253-1257.

(66) Li, R.; Wang, J.; He, Y.; Dong, F.; Bian, L.; Li, B. Mechanochemical Synthesis of Defective Molybdenum Trioxide, Titanium Dioxide, and Zinc Oxide at Room Temperature. ACS Sustainable Chem. Eng. 2019, 7 (14), 11985-11989.

(67) Su, F. Z.; He, L.; Ni, J.; Cao, Y.; He, H. Y.; Fan, K. N. Efficient and Chemoselective Reduction of Carbonyl Compounds with Supported Gold Catalysts under Transfer Hydrogenation Conditions. Chem. Commun. 2008, No. 30, 3531-3533.

(68) Zhu, H.; Ke, X.; Yang, X.; Sarina, S.; Liu, H. Reduction of Nitroaromatic Compounds on Supported Gold Nanoparticles by Visible and Ultraviolet Light. Angew. Chem., Int. Ed. 2010, 49 (50), 9657-9661.

(69) Xiao, Q.; Sarina, S.; Waclawik, E. R.; Jia, J.; Chang, J.; Riches, J. D.; Wu, H.; Zheng, Z.; Zhu, H. Alloying Gold with Copper Makes for a Highly Selective Visible-Light Photocatalyst for the Reduction of Nitroaromatics to Anilines. ACS Catal. 2016, 6 (3), 1744-1753. 
(70) Ke, X.; Zhang, X.; Zhao, J.; Sarina, S.; Barry, J.; Zhu, H. Selective Reductions Using Visible Light Photocatalysts of Supported Gold Nanoparticles. Green Chem. 2013, 15 (1), 236-244.

(71) Chaiseeda, K.; Nishimura, S.; Ebitani, K. Gold Nanoparticles Supported on Alumina as a Catalyst for Surface Plasmon-Enhanced Selective Reductions of Nitrobenzene. ACS Omega 2017, 2 (10), $7066-7070$

(72) Liu, Q.; Xu, Y.; Qiu, X.; Huang, C.; Liu, M. Chemoselective Hydrogenation of Nitrobenzenes Activated with Tuned Au/h-BN. J. Catal. 2019, 370, 55-60. 